\title{
Pentagon attempts to bend light to its will
}

\section{Geoff Brumfiel, Anaheim}

A research initiative is being launched by the Pentagon to investigate negatively refractive materials - structures that seem to defy basic physics by bending light the 'wrong' way.

A chunk of negatively refracting material about the size of a cheese wedge was on display at a technical meeting held last week by the Defense Advanced Research Projects Agency (DARPA) in Anaheim, California. DARPA officials say that it could be used in a variety of military technologies, including radar, communications and optics for lasers and imaging.

"We're looking to identify applications," says Valerie Browning, a programme manager at DARPA's Defense Sciences Office in Arlington, Virginia. The agency will unveil plans to study and apply these materials in military systems in the next month, Browning says.

Negative refraction was conceived in the 1960s, when theorists claimed that some materials should bend light in a strange way. When a beam of light passes from one material, such as air, to another, such as glass, it bends. This refraction is how glass lenses focus light. Negative refractive materials should bend light in the opposite direction to other substances (see diagram).

The idea remained speculative until 2001, when physicists at the University of California, San Diego, announced that they had made such a material. The structure was a 'metamaterial', an array of sheets of copper rings and wires, which could negatively refract microwaves.

Although some physicists were sceptical about the results (see Nature 420, 119-120; 2002), subsequent experiments have led most to accept the finding, says John Pendry, a physicist at Imperial College in London who works on negatively refracting materi-

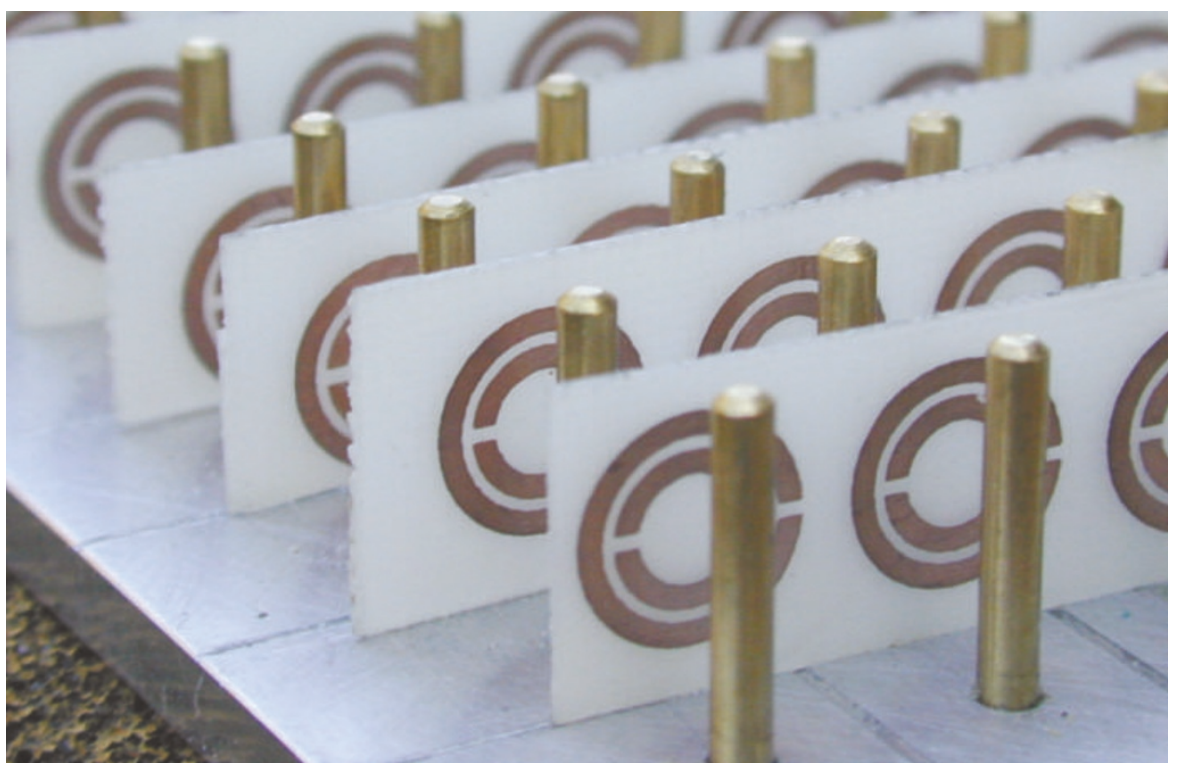

Fresh angle: metamaterials such as this copper-based structure have strange optical properties.

als. For example, George Eleftheriades and Anthony Grbic, physicists at the University of Toronto, have recently created a microwave lens from a negatively refracting structure (G. Eleftheriades and A. Grbic Phys. Rev. Lett. in the press).

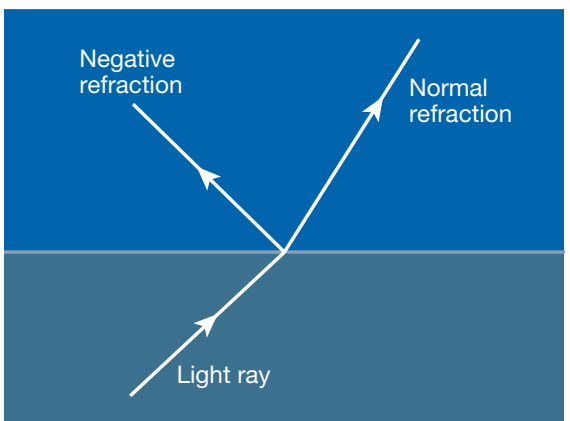

Negative refraction bends light in an unusual way.
Browning says that such advances convince her that the effect is real. But she still has questions about how the materials work. For example, some predict that the structures will amplify light waves that are normally dissipated by glass optics. If true, the material could make lenses that are more powerful than any possible with conventional optics. "But we're still unsure of the physics," Browning adds.

The new initiative will explore the physics and investigate the uses of negatively refracting materials in real systems. Researchers at the Boeing Corporation in Seattle are already investigating negatively refracting materials as optics for steering radar and radio communications, Browning says. And if new materials can be developed to bend infrared or even visible light, the applications could be even broader.

\section{Biomedical institute wins reprieve from relocation}

\section{Laura Nelson, London}

Plans to move Britain's National Institute for Medical Research to a site outside London have been scrapped, according to a task force run by the institute's funders, the Medical Research Council (MRC).

The announcement is a partial victory for the institute's researchers, who protested last year when the MRC suggested moving the centre to Addenbrookes Hospital in Cambridge. The move was intended to improve links between clinical and basic researchers (see Nature 423, 573; 2003).

But it will not end the uncertainty surrounding the future of the institute, based in Mill Hill in north London. The task force says that the centre needs to support more clinical studies, and may be better off closer to London hospitals.

The group was set up after last June's protests, and is chaired by MRC chief executive Colin Blakemore. Results of an 8 February meeting, published on 4 March, show that the task force rejected options to close the institute, move it, or sell its site and spread the work around other London institutes.

But the group has not decided whether the institute will stay where it is, with added facilities for clinicians, or move to a more central site. "Both options require substantial investment," notes taskforce member Robin Lovell-Badge, a developmental geneticist at the institute. Funding issues will be discussed at the next meeting on 18 April.

The need for greater clinical integration, emphasized by task-force suggestions that the institute's name be changed to the MRC National Institute for Human Health, has already been made a priority by Blakemore. The move mirrors the situation in the United States, where the National Institutes of Health is attempting to channel basic research in areas such as genomics into clinical advances. 